Short communication

\title{
Analysis of crab meat volatiles as possible spoilage indicators for blue crab (Callinectes sapidus) meat by gas chromatography-mass spectrometry
}

\author{
Paul J. Sarnoski ${ }^{\mathrm{a}, *}$, Sean F. O’Keefe ${ }^{\mathrm{a}}$, Michael L. Jahncke ${ }^{\mathrm{b}}$, Parameswarakumar Mallikarjunan ${ }^{\mathrm{c}}$, \\ George J. Flick ${ }^{\mathrm{a}}$
}

a Department of Food Science and Technology, Virginia Polytechnic Institute and State University, Blacksburg, VA 24061, USA

${ }^{\mathrm{b}}$ Department of Food Science and Technology, Virginia Seafood Agricultural Research and Extension Center, Hampton, VA 23669, USA

${ }^{\mathrm{c}}$ Department of Biological Systems Engineering, Virginia Polytechnic Institute and State University, Blacksburg, VA 24061, USA

\section{A R T I C L E I N F O}

\section{Article history:}

Received 4 June 2009

Received in revised form 12 February 2010

Accepted 16 March 2010

\section{Keywords:}

Mass spectrometry

Gas chromatography

Blue crab

Solid-phase microextraction

Spoilage

Indole

Trimethylamine

\begin{abstract}
A B S T R A C T
Traditionally crab meat spoilage has been evaluated using sensory panels. A method was developed using solid-phase microextraction-gas chromatography-mass spectrometry (SPME-GC-MS) to examine the aroma profile of blue crab (Callinectes sapidus) for chemical indicators of spoilage. The chemicals found to correlate best with spoilage were trimethylamine (TMA), ammonia, and indole over a period of 7 days. In addition, chemicals previously not identified in the aroma profile of blue crab were tentatively detected. Scan mode of the mass spectrometer was used to qualitatively determine compounds extracted from the volatile profile of spoiling blue crab by the SPME fiber. Selected ion monitoring (SIM) mode of the mass spectrometer improved resolution, identified compounds at low concentrations, and allowed spoilage related compounds to be detected in one chromatographic run without sample heating. TMA increased linearly. A significant difference in TMA concentrations were found for day 0 and day 4 samples. Indole concentrations corresponded well with sensory and microbial evaluations, in early, mid and highly spoiled crab meat samples.
\end{abstract}

(c) 2010 Elsevier Ltd. All rights reserved.

\section{Introduction}

Seafood is more perishable, compared with other muscle foods such as beef, pork, chicken, etc. For this reason it requires more careful handling and storage. Most commercially harvested fishery products are landed at ports far removed from the point of harvest. Poor handling practices on board ships and on shore can cause deterioration in fish and shellfish quality before it is sold to the consumer (Ashie, Smith, \& Simpson, 1996). Similarly, blue crab meat deteriorates rapidly at refrigerated temperatures (Akpan, 1997; Farragut, 1965). Its high moisture content and loose connectivity between the collagen fibers provide a rich environment for microbial growth (Suyama \& Konosu, 1987). Crab meat has a higher composition of free amino acids compared with finfish and the mechanism of decomposition is somewhat different. Blue crabs contain minor amounts of carbohydrates, and are rich in calcium, phosphorous, magnesium, sodium, potassium, manganese, zinc, and iron (Gökoðlu \& Yerlikaya, 2003; Lopez, Williams, \& Ward, 1981).

In the post-mortem animal, spoilage microorganisms metabolize shellfish muscle, producing a wide variety of volatile off-fla-

\footnotetext{
* Corresponding author. Tel.: +1 570231 6806; fax: +1 5702319293

E-mail address: sarnospj@vt.edu (P.J. Sarnoski).
}

vors and odors. Persistent ammonia odors are used by sensory experts as an indicator of spoilage in crab meat and some other seafood products. Trimethylamine (TMA), a volatile amine, is responsible for an unpleasant fishy odor and is used as a quality index for seafood (Spink et al., 1996). Indole has been used as a spoilage indicator for shrimp and other crustaceans (Snellings, Takenaka, Kim-Hayes, \& Miller, 2003). Other compounds produced during spoilage include hydrogen sulfide, dimethyl sulfide, and methyl mercaptan from sulfur-containing amino acids; various amines, ammonia, skatole, putrescine, and cadaverine from amino acids; lower fatty acids from sugars such as glucose and ribose; carbonyl compounds from lipids (Avery \& Lamprecht, 1988; Smith, Nickelson, Martin, \& Finne, 1984; Watts \& Brown, 1982). Loss of freshness, which often precedes microbial spoilage, primarily involves autolytic reactions controlled by endogenous enzymes present in the muscle tissue as well as those leaching from the gut (Ashie et al., 1996).

Volatile chemical profiles associated with crab meat have not been extensively studied, since extraction of these compounds is difficult and aroma compounds are at low concentrations. Dynamic headspace sampling (DHS) and simultaneous steam distillationsolvent extraction (SDE) have been used as volatile extraction techniques to investigate the volatile profiles of crab (Chung \& Cadwallader, 1993; Matiella \& Hsieh, 1990). These procedures 
are laborious and, due to the excessive heating of the sample, artifact formation is likely.

Pawliszyn's group (1997) was the first to use solid-phase microextraction (SPME) for environmental analyses. The technique is now widely used for environmental analyses (Powers, van Kempen, Bundy, Sutton, \& Hoff, 2000; Robacker \& Bartelt, 1996) as well as for identifying volatiles in food (Jones, Ewen, \& Ratcliffe, 1998; Laguerre, Mestres, Davrieux, Ringuet, \& Boulanger, 2007; Mildner-Szkudlarz, Jeleń, Zawirska-Wojtasiak, \& Wąsowicz, 2003). The technique uses an inert fiber coated with an adsorbent (for which there are several choices). The adsorbent is placed in the headspace of a sample and allowed to adsorb volatiles. The fiber is then thermally desorbed in the injection port of a GC, and the released volatiles are analyzed. The main advantages of SPME are that no solvents are required, it is easy to use, sensitive, inexpensive and rapid. In addition, SPME can be automated, when used in conjunction with an autosampler for rapid, routine analyses (Ugland, Krogh, \& Rasmussen, 1999).

The objective of this study was to find an analytical method that could be used to identify chemical indicators of spoilage in crab meat.

\section{Materials and methods}

\subsection{Blue crab samples for GC-MS analysis}

Experiments were conducted using cooked and picked Atlantic Blue Crab (Callinectes sapidus) body meat (i.e., regular or special) obtained from a local crab processing company (Hampton, VA, USA) harvested from the Chesapeake Bay. The harvest season on the East Coast is from April to October. Crabs were processed according to the standard commercial procedure. Raw harvested crabs were placed into a pressurized retort and cooked under pressure at $121^{\circ} \mathrm{C}$ for $7-10 \mathrm{~min}$. The crabs were then air cooled and placed in refrigeration $\left(2^{\circ} \mathrm{C}\right)$ prior to picking. The picking and packing process is completed within $2.5 \mathrm{~h}$. After packing, the crab meat is placed into refrigerated storage. The samples used in this study were harvested after the picking stage and vacuum packed in SealPak pouches ( $0.47 \mathrm{~L}, 2.5$ mil polyethylene terephthalate/linear lowdensity polyethylene, Kapak, Minneapolis, MN, USA) containing approximately $100-200 \mathrm{~g}$ portions that were immediately frozen (day 0 samples) or after controlled spoilage. Reference ( 0 day) samples were portioned, then first frozen at $-18^{\circ} \mathrm{C}$ for $12-20 \mathrm{~h}$ in a still storage freezer and then stored at $-80^{\circ} \mathrm{C}$ in a still freezer. The remaining samples were sequentially spoiled and portioned at $4,5,6$, and 7 days under refrigerated storage conditions $\left(4^{\circ} \mathrm{C}\right)$, frozen at $-18{ }^{\circ} \mathrm{C}$ for $12-20 \mathrm{~h}$ and then stored at $-80^{\circ} \mathrm{C}$ until needed for analysis.

Samples were thawed overnight in the bag, in a refrigerator $\left(4^{\circ} \mathrm{C}\right.$ ) before analysis. Samples were brought to $40{ }^{\circ} \mathrm{C}$ in the bag using a water bath. Bags were Stomachered for $1 \mathrm{~min}$ at 230 RPM (Seward, Stomacher ${ }^{\circledR} 400$ Circulator, Worthing, UK). Twenty grams were removed from the bag and put into a $40 \mathrm{~mL}$ headspace vial, fitted with a Teflon-lined septum. Headspace was allowed to accumulate at room temperature for 5 min before piercing the septum with the SPME fiber assembly and protracting the fiber inside the vial.

\subsection{Volatile compound analysis}

A $65 \mu \mathrm{m}$ polydimethylsiloxane/divinylbenzene (PDMS/DVB) StableFlex ${ }^{\mathrm{TM}}$ fiber (Supelco Inc., Bellefonte, PA, USA) was used for the SPME headspace sampling. The fiber was conditioned prior to use in the gas chromatograph injection port at $270{ }^{\circ} \mathrm{C}$ for $0.5 \mathrm{~h}$. Volatiles were adsorbed for $15 \mathrm{~min}$ at ambient temperature $\left(\sim 21^{\circ} \mathrm{C}\right)$ or with the vial submerged in boiling water $\left(99.7^{\circ} \mathrm{C}\right)$. After adsorption, the fiber contained in the assembly was then immediately inserted and protracted into the injection port of the gas chromatograph and the run was started manually. The fiber was left in the injection port for $4 \mathrm{~min}$ and then removed. A GC-17A gas chromatograph coupled to a QP5050A MSD quadrupole mass spectrometer (Shimazdu Scientific Instruments, Inc., Columbia, MD, USA) was used for the analyses. The GC-17A was equipped with a DB5-MS column (60 m length $\times 0.25 \mathrm{~mm}$ i.d. $\times 1 \mu \mathrm{m}$ film thickness, J \& W Scientific, Folsom, CA, USA). Operating conditions for the GC were: splitless mode using a narrow bore SPME insert, helium flow $0.7 \mathrm{~mL} \mathrm{~min}^{-1}$, linear velocity $22 \mathrm{~cm} \mathrm{~s}^{-1}$, initial oven temperature $50{ }^{\circ} \mathrm{C}(5 \mathrm{~min}$ hold $)$, then $10^{\circ} \mathrm{C}$ per minute linear ramp to $300{ }^{\circ} \mathrm{C}(10 \mathrm{~min}$ hold $)$, injector $270^{\circ} \mathrm{C}$, interface $230^{\circ} \mathrm{C}$. The mass spectrometer was operated both in scan and selected ion monitoring (SIM) modes, GC conditions were the same for both analyses. For scan mode, the scan range in mass-to-charge ratios $(\mathrm{m} / \mathrm{z})$ was $15-450$, solvent cut time $5 \mathrm{~min}$, MS start time $5.2 \mathrm{~min}$. For SIM mode, the following $\mathrm{m} / \mathrm{z}$ was selected: $15,30,42,58,59,62$, $63,89,90$, and 117 . The solvent cut time was $4.5 \mathrm{~min}$, and MS start time was $4.6 \mathrm{~min}$ for SIM mode. All sample groups were run in triplicate. Volatile compounds were identified by comparison of retention indices and mass spectra with authentic standards for ammonia, TMA, and indole (Sigma-Aldrich, St. Louis, MO, USA), all of which were analytical grade. Due to the volatile fleeting nature of dimethyl sulfide, a standard that yielded consistent results for this compound could not be purchased. For this reason changes in the amount of dimethyl sulfide present were obtained as area counts from the integration software of the instrument. The remaining compounds were identified tentatively using the Wiley Registry of Mass Spectral Data, 7th Edition (McLafferty, 2000).

\subsection{Quantitative analysis for spoilage compounds}

Quantitative values for ammonia, TMA, and indole in blue crab meat were determined by use of five sample concentrations for the standard curves using analytical grade standards (Sigma-Aldrich). Aqueous solutions of the standards were made and comparison of retention time and mass spectra functioned as positive identification of the aforementioned compounds in blue crab meat.

\subsection{Microbial and sensory analysis}

Fresh cooked and picked crab meat was collected from the local crab processing plant and held on ice at refrigeration temperatures $\left(<4^{\circ} \mathrm{C}\right)$ for $1 \mathrm{~h}$. Crab meat was divided into $2.27 \mathrm{~kg}(5 \mathrm{lb})$ sub-samples and spread into 25 by $40 \mathrm{~cm}$ lidded plastic containers for 0,4 , 5,6 , and 7 days of controlled decomposition at $4{ }^{\circ} \mathrm{C}$. Crab meat was periodically sampled, sensory quality examined, packaged in 100$200 \mathrm{~g}$ portions in Kapak SealPak pouches $(0.47 \mathrm{~L}, 16.5 \mathrm{~cm} \times$ $20.3 \mathrm{~cm}$ ), vacuum sealed, labeled, and frozen overnight at $-18{ }^{\circ} \mathrm{C}$ before placement at $-80{ }^{\circ} \mathrm{C}$ for storage.

Initial bacterial load was enumerated using standard AOAC approved methods as listed in the FDA Bacteriological Analytical Manual (FDA, 2001). Twenty-five gram portions of well-mixed crab meat were blended with $225 \mathrm{~mL}$ sterile $0.1 \%$ peptone buffer (Oxoid, Basingstoke, Hampshire, UK) in a Stomacher bag and Stomachered for $2 \mathrm{~min}$ at $230 \mathrm{RPM}$ for a 1:10 dilution. Subsequent dilutions were prepared by adding $1 \mathrm{~mL}$ to $9 \mathrm{~mL}$ of sterile peptone broth. One milliliter portions were plated on $3 \mathrm{M}$ Petrifilm aerobic count plates ( $3 \mathrm{M}$ Microbiology, St. Paul, MN, USA) and incubated at $35^{\circ} \mathrm{C}$ for $48 \mathrm{~h}$. Aerobic plate counts (APC) were reported as colony forming units per gram of $\mathrm{crab}(\mathrm{cfu} / \mathrm{g})$.

Spoiled crab meat was evaluated for odor, taste and texture, against reference (day 0) samples using a 6 member trained sensory panel. Panelists were selected based on their ability to accu- 
rately identify different intensities of sweet, sour, bitter, salty, ammonia, card-boardy, fishy, rancid, and earthy reference samples. These samples were actual food samples specified to be used as references according to the Spectrum ${ }^{\mathrm{TM}}$ Descriptive Analysis Method (Meilgaard, Civille, \& Carr, 2007). Prior to the start of this study, the sensory panelists underwent training for 8-12 months based upon the Spectrum ${ }^{\mathrm{TM}}$ Descriptive Analysis Method to evaluate the attributes of blue crab meat samples using known crab meat samples that were unspoiled, and samples from the same group that were spoiled under controlled refrigeration $\left(4^{\circ} \mathrm{C}\right)$. A complete range of spoilage characteristics was evaluated. Crab meat sample classifications (e.g., high pass, mid-pass, low pass, low fail, and high fail) were based on group consensus using a combination of several odor and flavor sensory intensity attributes. This group consensus led to the following description of crab meat spoilage: as the crab meat was held in refrigerated storage, sweetness intensity declined and eventually dissipated completely. Moderate crab like attributes became less intense, and eventually dissipated completely, the texture became softer. The crab meat began to develop sour odors and flavors which increased in intensity, along with slight bitterness and slight to moderate ammonia odors.

For the actual sensory evaluation study, coded unknown crab meat samples were used. Sensory descriptor terms developed from the training sessions using unspoiled and spoiled known crab meat samples were used to classify these unknown crab meat samples into categories. Before evaluation, samples were removed from $-80^{\circ} \mathrm{C}$ storage and thawed overnight in a refrigerator $\left(4^{\circ} \mathrm{C}\right)$. Packages were opened and the crab meat was placed into $59.1 \mathrm{~mL}$ ( $2 \mathrm{oz}$ ) lidded plastic cups. Reference samples specified by the Spectrum $^{\mathrm{TM}}$ Descriptive Analysis Method representing different food intensity attributes were provided to the panelists prior to evaluating the crab meat samples for guidance purposes. Each panelist received in random order replicates of each sample during each evaluation session. The entire sensory evaluation was repeated the following day. Sensory and microbiological analyses were conducted at the Virginia Seafood Agricultural Research and Extension Center, Hampton, Virginia.

\subsection{Statistical analysis}

JMP IN 7.0.1 (SAS Institute, Cary, NC, USA) was used for statistical analysis of the GC-MS data. Analysis of variance (ANOVA) was performed on the group means of spoiled crab meat. Differences between groups were considered significant when means differed at the $p \leqslant 0.05$ level of significance using a Fisher's LSD (Student's t) procedure.

\section{Results and discussion}

The three chemicals that best correlated with the established methods of sensory and microbial analyses for blue crab meat were ammonia, TMA, and indole (Table 1). The presence of persistent ammonia odor is an indicator of spoilage in some fishery products (USDC, 2009). Ammonia is typically used to evaluate fish quality using an ammonia ion-selective electrode (ISE) but this technique measures "apparent ammonia" which includes other amines, not only ammonia (Pivarnik, Ellis, Wang, \& Reilly, 2001). This will lead to a greater amount of ammonia being detected by the ISE technique than truly exists in the sample. In this study the scan mode of the GC-MS was not sufficiently selective to determine the presence of ammonia, as the ammonia co-eluted with water. Using the SIM mode, ammonia was distinguished from water at $\mathrm{m} / \mathrm{z} 15$. The base peak of ammonia is $\mathrm{m} / \mathrm{z} 17$, water also fragments at $\mathrm{m} / \mathrm{z} 17$ leading to interference. Thus, it was difficult to determine which part of the peak could be attributed to water, and which part of the peak could be attributed to ammonia. However, ammonia has a minor peak intensity at $\mathrm{m} / \mathrm{z} 15$, and water does not interfere with this peak. Thus, peak intensity at m/z 15 was used to calculate the concentration of ammonia present in the headspace upon comparison with a standard solution of ammonia in water at various levels. Existence of ammonia was also confirmed via a retention time match with the ammonia standard.

TMA is used as an indicator of spoilage in marine species. Concentrations of TMA can range from 0.5 to $59 \mathrm{ppm}$ in fresh and frozen hake and 3.8 to $15.3 \mathrm{ppm}$ in frozen crab meat (Spink et al., 1996; Yerlikaya \& Gökoðlu, 2004). In this study, TMA was separated from water (eluting just after water) and was positively identified using either SIM or scan mode (Figs. 1 and 2). When the samples were heated, separation of the TMA peak from water was difficult since an appreciable amount of water was partitioned into the headspace and tailed into the TMA peak. The SPME fiber does not appreciably adsorb water (Robacker \& Bartelt, 1996) but crab meat contains roughly $80 \%$ moisture, and since it was the major volatile present in the headspace some was adsorbed by the fiber. Using the SIM mode, water-derived background fragments were avoided, and a narrow peak without tailing was obtained (Fig. 2). TMA concentrations increased linearly, and there was a significant increase of TMA from day 0 to day 4 in refrigerated samples (Table 1), suggesting that TMA may be used as a sensitive means of evaluating the early stages of spoilage in crab meat. Aerobic plate counts and sensory analysis showed little difference between day 0 and day 4 samples (Table 2), signifying that TMA may be a more receptive indicator of the earlier stages of spoilage than those methods.

Indole has been used as an indicator of spoilage in shrimp (Snellings et al., 2003). In this study indole could be detected using scan mode when the sample was heated $\left(99.7^{\circ} \mathrm{C}\right)$. Without heating, insufficient concentrations of indole were volatilized into the headspace to be detected using scan mode. However, indole was able to be detected in SIM mode without heating. Using SIM mode increased the mass spectrometer sensitivity, because only a few $\mathrm{m} / \mathrm{z}$ are examined instead of a range of $\mathrm{m} / \mathrm{z}$. In addition, since the samples were not heated again, the probability of artifact formation was reduced. The use of SIM mode without heating also led to the detection of all of the other identified spoilage indicating chemicals in one chromatographic run (Fig. 2) without interference. Indole concentrations changed little in the early stages of spoilage. No significant difference was seen in indole concentration for day 0 and day 4 samples, or day 5 and

Table 1

ANOVA analysis of spoilage indicating chemicals analyzed via SPME-GC-MS.

\begin{tabular}{|c|c|c|c|c|}
\hline Sample & Ammonia $(\mu \mathrm{g} / \mathrm{mL})$ & TMA $(\mu \mathrm{g} / \mathrm{mL})$ & Indole $(\mu \mathrm{g} / \mathrm{mL})$ & Dimethyl sulfide (area counts $\times 10^{4}$ ) \\
\hline 0 day & $5.33 \mathrm{a} \pm 0.83$ & $6.69 \mathrm{a} \pm 1.23$ & $1.64 a \pm 0.18$ & $0.42_{\mathrm{a}} \pm 0.06$ \\
\hline 4 day cold & $7.57_{\mathrm{ab}} \pm 0.44$ & $21.7_{b} \pm 2.42$ & $1.73_{\mathrm{a}} \pm 0.07$ & $63.3_{b} \pm 9.93$ \\
\hline 5 day cold & $7.72_{\mathrm{ab}} \pm 1.38$ & $30.3_{c} \pm 2.16$ & $6.23_{b} \pm 0.51$ & $58.0_{\mathrm{b}} \pm 4.74$ \\
\hline 6 day cold & $12.0_{\mathrm{b}} \pm 2.13$ & $30.7_{c} \pm 0.91$ & $7.34_{b} \pm 0.30$ & $194_{c} \pm 8.32$ \\
\hline 7 day cold & $20.5_{c} \pm 1.88$ & $40.8_{\mathrm{d}} \pm 2.47$ & $22.5_{c} \pm 0.88$ & $62.5_{b} \pm 4.25$ \\
\hline
\end{tabular}

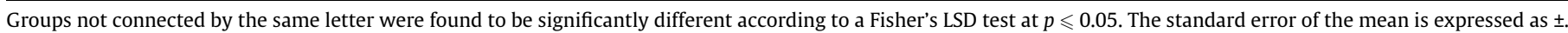




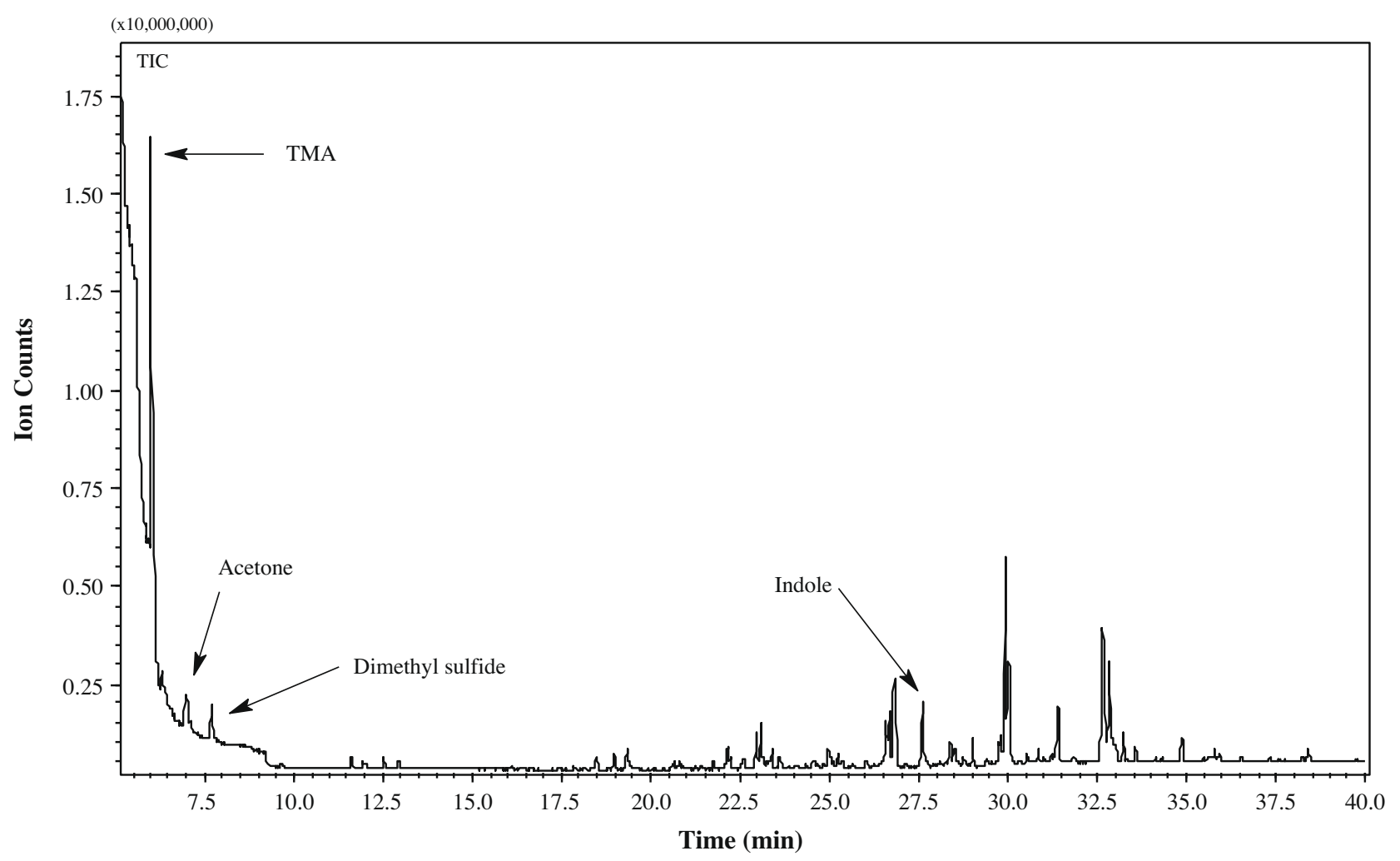

Fig. 1. Example of a scan mode chromatogram (sampled at $99.7^{\circ} \mathrm{C}$ ).

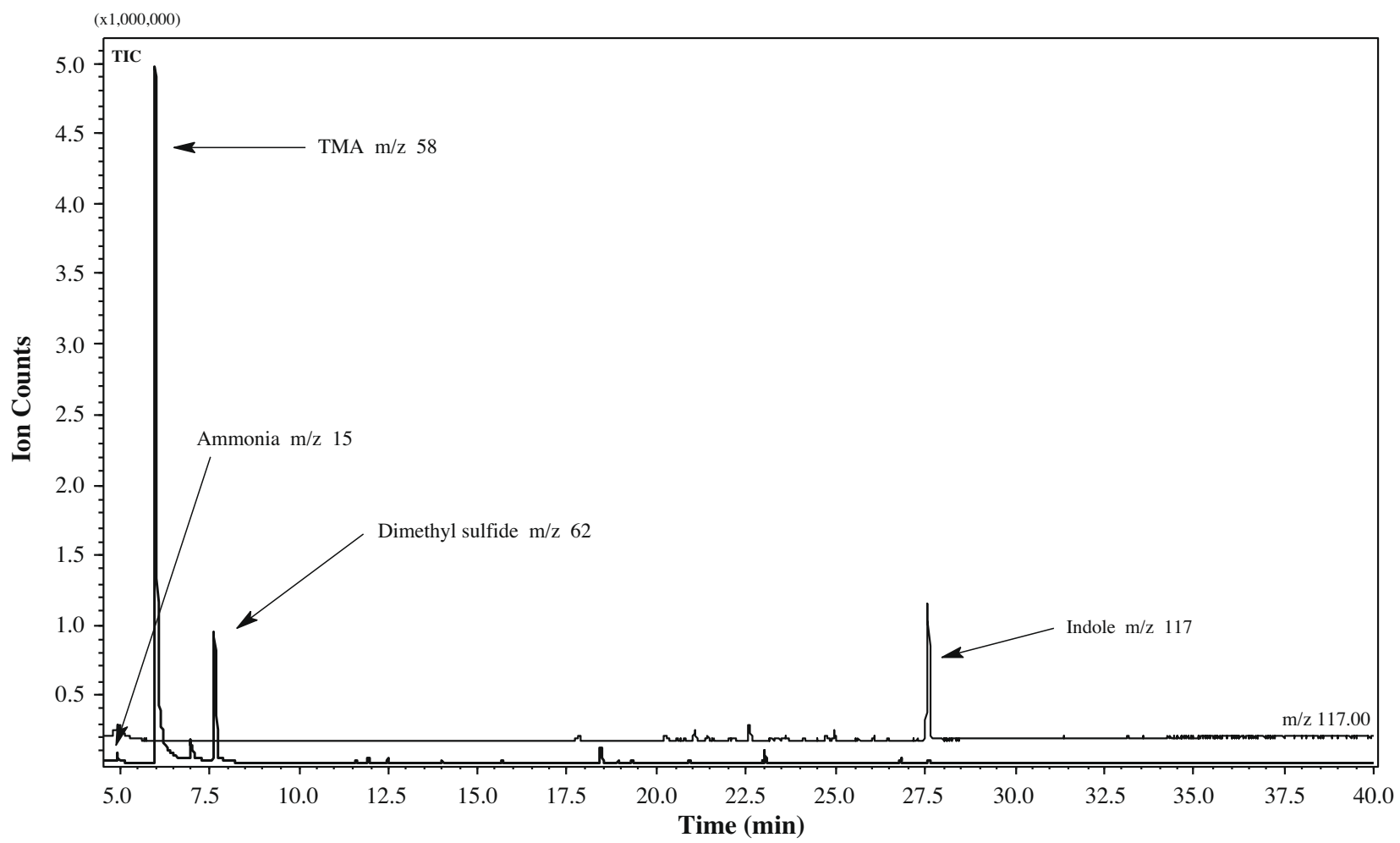

Fig. 2. SIM mode chromatogram (Ambient, $\sim 21{ }^{\circ} \mathrm{C}$ ). Offset is the $\mathrm{m} / \mathrm{z} 117$ selected ion.

day 6 samples (Table 1 ). A significant difference was found between these samples and a day 7 sample. This agrees well with sensory and APC group classification (Tables 1 and 2). In addition, indole followed an exponential curve (Fig. 3) indicative of microbial spoilage, suggesting it may be a good chemical indicator of microbial growth in crab meat. 
Table 2

Aerobic plate counts (APC) and sensory results.

\begin{tabular}{lll}
\hline Sample & APC $(\mathrm{cfu} / \mathrm{g})$ & Sensory result \\
\hline Reference (0 day) & $1.65 \times 10^{5}$ & Mid-Pass $^{\mathrm{a}}$ \\
4 day cold & $8.5 \times 10^{5}$ & Mid-Pass $^{\mathrm{a}}$ \\
5 day cold & $1.6 \times 10^{6}$ & Low Pass $^{\mathrm{a}}$ \\
6 day cold & $3.2 \times 10^{6}$ & Low Fail $^{\mathrm{b}}$ \\
7 day cold & $1 \times 10^{7}$ & High Fail $^{\mathrm{b}}$ \\
\hline
\end{tabular}

a Classifications by panel consensus based on changes in intensity of sweetness, and crab like odor and flavors and the absence of sour, ammonia, bitter odors and flavors.

b Classifications by panel consensus based on less intense to neutral sweetness and crab like odors and flavors along with development and increase in intensity for sour, ammonia, and bitter odors and flavors.

In this study, the peaks from retention time $12 \mathrm{~min}$ to $35 \mathrm{~min}$ were mainly of unknown origin except for indole, there were no correlations of these unknown compounds with crab meat spoilage (Fig. 1). These compounds most likely appear due to the specificity of the SPME fiber for medium length hydrocarbons especially with heating (thus increasing their volatility and adsorption).

In a study by Baek and Cadwallader (1997) possible routes of formation of various volatile compounds in seafood products were discussed. The reaction of 12- or 15-lipoxygenases and hydroperoxide lyase on eicosapentaenoic acid (EPA) is thought to be responsible for the formation of volatile 6-, 8-, and 9-carbon carbonyls and alcohols such as 1-octen-3-ol (Table 3 ). Through hydroperoxide decomposition as a result of autoxidation, methyl linoleate will decompose to pentanal (Table 3 ) as one of its minor products (Frankel, 1998). Polyunsaturated fatty acids present in shellfish are also susceptible to autoxidation.

It is possible that compounds identified in this study such as hexadecanal, 1,13-tetradecadiene, octadecanal, styrene etc. (Table 3) may be associated with environmental contaminants. Low concentrations of these types of compounds in the aquatic environment are not unusual and have been reported in other studies (Table 3). Other compounds commonly associated with seafood contamination include polychlorinated biphenyls (PCBs) (Storelli, Giacominelli-Stuffler, Storelli, \& Marcotrigiano, 2003). Polyaro-
Table 3

Comparison of aroma compounds identified in different studies of crab meat products. In this study presence was determined by mass spectrum library match, unless otherwise indicated.

\begin{tabular}{|c|c|c|c|}
\hline Chemical compounds & $\begin{array}{l}\text { Present } \\
\text { study }\end{array}$ & $\begin{array}{l}\text { Matiella and } \\
\text { Hsieh (1990) }\end{array}$ & $\begin{array}{l}\text { Chung and } \\
\text { Cadwallader } \\
\text { (1993) }\end{array}$ \\
\hline \multicolumn{4}{|l|}{ Aldehydes } \\
\hline Pentanal & $\mathrm{x}$ & $\mathrm{x}$ & \\
\hline Hexadecanal & $\mathrm{x}$ & & \\
\hline Octadecanal & $\mathrm{x}$ & & \\
\hline \multicolumn{4}{|l|}{ Alkanes/Alkenes } \\
\hline Hexadecane & $\mathrm{x}$ & & $\mathrm{x}$ \\
\hline $\begin{array}{l}\text { 1,13-Tetradecadiene } \\
\text { Aromatics }\end{array}$ & $\mathrm{x}$ & & \\
\hline Styrene & $\mathrm{x}$ & $\mathrm{x}$ & $\mathrm{x}$ \\
\hline $\begin{array}{l}\text { Butylated } \\
\text { hydroxytoluene } \\
\text { Alcohols }\end{array}$ & $\mathrm{x}$ & & \\
\hline 3-Methyl-1-butanol & $\mathrm{x}$ & & $\mathrm{x}$ \\
\hline 1-Hexanol & $\mathrm{x}$ & & $\mathrm{x}$ \\
\hline \multicolumn{4}{|l|}{ Ketones } \\
\hline 2-Propanone & $\mathrm{x}$ & & $\mathrm{x}$ \\
\hline 2-Pentanone & $\mathrm{x}$ & $\mathrm{x}$ & \\
\hline 2-Heptanone & $\mathrm{x}$ & & $\mathrm{x}$ \\
\hline 2-Nonanone & $\mathrm{x}$ & & $\mathrm{x}$ \\
\hline 2-Undecanone & $\mathrm{x}$ & & $\mathrm{x}$ \\
\hline \multicolumn{4}{|l|}{$\begin{array}{l}\text { Miscellaneous } \\
\text { compounds }\end{array}$} \\
\hline Dimethyl sulfide & $\mathrm{x}$ & $\mathrm{x}$ & $\mathrm{x}$ \\
\hline Limonene & $\mathrm{x}$ & $\mathrm{x}$ & $\mathrm{x}$ \\
\hline Trimethylamine & $\mathrm{x}$ & & $\mathrm{x}$ \\
\hline Indole ${ }^{*}$ & $\mathrm{x}$ & & $\mathrm{x}$ \\
\hline
\end{tabular}

Indicates that presence was also confirmed by running an analytical standard.

matic hydrocarbons (PAHs), chlordane, hexachlorobenzene, hexachlorocyclohexane, along with other metal contaminants were found in seafood from Quincy Bay in Massachusetts (Cooper, Doyle, \& Kipp, 1991). Polychlorinated dibenzo-p-dioxins/dibenzofurans (PCDD/Fs) were found at trace levels in 147 food samples including 10 blue crab, 8 lobster, and 10 crawfish samples (Hayward et al., 2001).

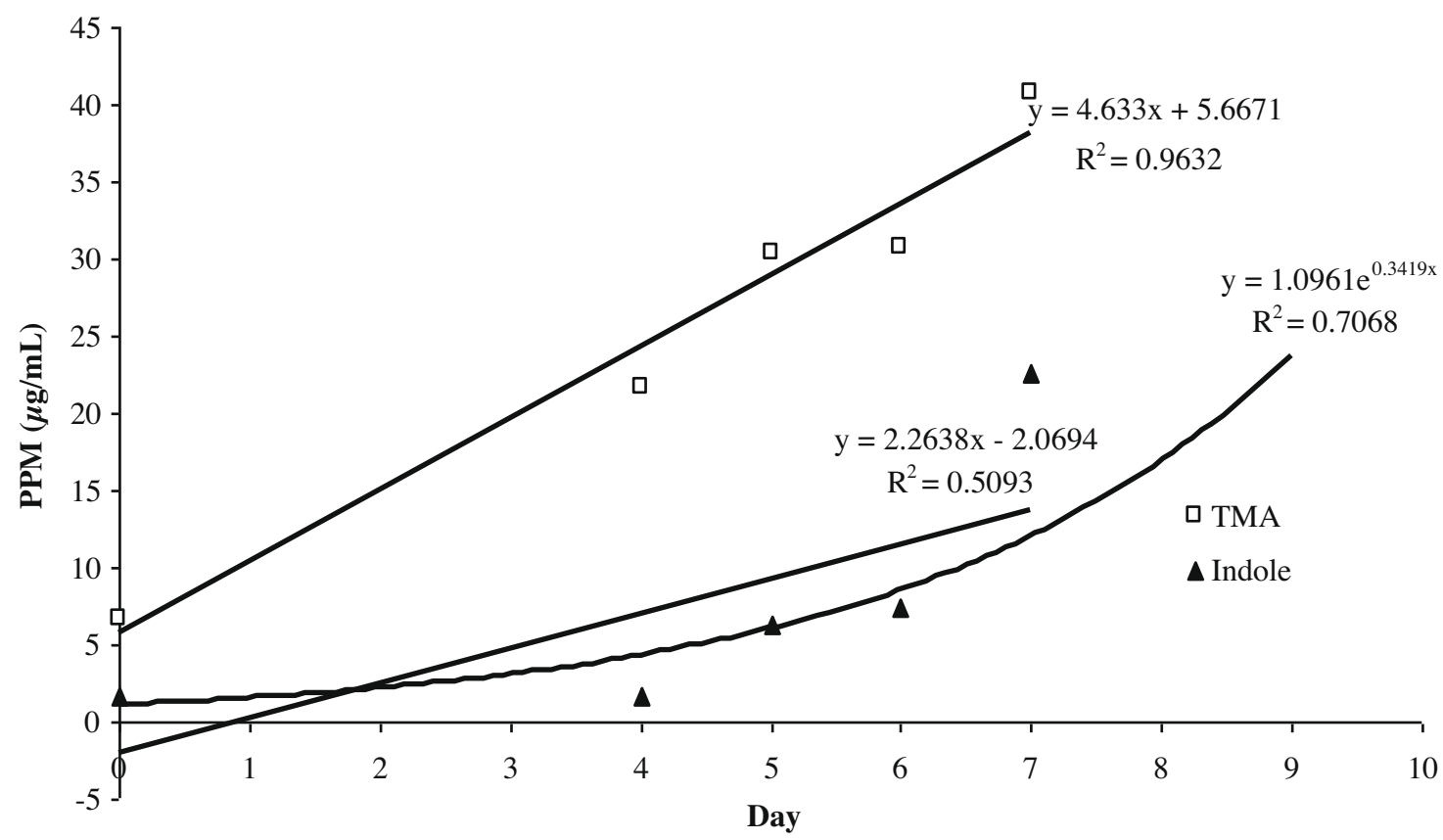

Fig. 3. Curves representing the development of TMA and indole presence in spoiling blue crab meat. Each point is an average of three trials. 
Dimethyl sulfide in this study may have been derived from the breakdown of dimethylsulfoniopropionate (DMSP) in coastal waters by marine phytoplankton and seaweeds. There is evidence to suggest that the breakdown of DMSP can be caused by enzymatic or microbial action (Kiene, 1990). The area count for dimethyl sulfide was at its highest for day 6 samples and then decreased for the day 7 samples (Table 1). It is possible that the sulfur metabolizing microorganisms may have been more active at this point, and by day 7 became less active in the crab meat matrix. Or perhaps, the enzyme responsible for the breakdown reached its maximum activity on day 6 .

An interesting finding was the presence of butylated hydroxytoluene (BHT) in the heated SPME extracted sample procedure. At first, its presence was puzzling since the crab meat samples were not treated with an antioxidant dip. A possible explanation is that the BHT migrated from the packaging material into the crab meat during sample heating. The antioxidant BHT has been found to migrate from high-density polyethylene and low-density polyethylene films into food (Hoojjat, Harte, Hernandez, Giacin, \& Miltz, 1987; Miltz et al., 1988; Schwope et al., 1987). It is a smaller, more volatile molecule compared with other antioxidants. Therefore, it is possible that heating the sample to approximately $100{ }^{\circ} \mathrm{C}$ caused BHT to partition into the gas phase in appreciable amounts for adsorption by the SPME fiber and detection by GC-MS

The two most useful indicators of spoilage were found to be indole and TMA. The data indicates that TMA may serve as a useful chemical indicator for the early stages of spoilage. Indole was found to serve as a useful chemical indicator for the latter stages of spoilage. The most efficient method for identifying all the spoilage related chemicals was by using SIM mode of the mass spectrometer which allowed for rapid, sensitive, and selective detection of the compounds of interest.

\section{Acknowledgements}

Funding for this research was provided by the Virginia Sea Grant Program, the World Food Logistics Organization and the International Association of Refrigerated Warehouses (WFLO/ IARW) and by the National Fisheries Institute (NFI) Fishery Scholarship Fund (FSF).

\section{References}

Akpan, E. J. (1997). Proximate composition of edible blue crab Callinectus sapidus. Journal of Food Science and Technology, 34(1), 59-60.

Ashie, I. N., Smith, J. P., \& Simpson, B. K. (1996). Spoilage and shelf-life extension of fresh fish and shellfish. Critical Reviews in Food Science and Nutrition, 36(1-2) 87-121.

Avery, J. J. W., \& Lamprecht, A. (1988). The shelf-life extension of fresh hake through gamma irradiation. Food Review, 15(Suppl.), 28

Baek, H. H., \& Cadwallader, K. R. (1997). Character-impact aroma compounds of crustaceans. In F. Shahidi, \& K. R. Cadwallader (Eds.), Flavor and lipid chemistry of seafoods (pp. 85-94). Washington, DC: American Chemical Society.

Chung, H. Y., \& Cadwallader, K. R. (1993). Volatile components in blue crab (Callinectes sapidus) meat and processing by-product. Journal of Food Science, 58(6), 1203-1211.

Cooper, C. B., Doyle, M. E., \& Kipp, K. (1991). Risks of consumption of contaminated seafood: the Quincy Bay case study. Environmental Health Perspectives, 90, 133-140.

Farragut, R. N. (1965). Proximate composition of Chesapeake Bay blue crab (Callinectes sapidus). Journal of Food Science, 30, 538-544.

FDA. (2001). Bacteriological analytical manual online - aerobic plate count (Vol. 2009). US Food and Drug Administration. http://www.fda.gov/Food/ScienceResearch/ LaboratoryMethods/BacteriologicalAnalyticalManualBAM/ucm063346.htm (accessed 20.8.09)

Frankel, E. N. (1998). Lipid oxidation (p. 303). Dundee, Scotland: The Oily Press.
Gökoðlu, N., \& Yerlikaya, P. (2003). Determination of proximate composition and mineral contents of blue crab (Callinectes sapidus) and swim crab (Portunus pelagicus) caught off the Gulf of Antalya. Food Chemistry, 80, 495-498.

Hayward, D. G., Holcomb, J., Glidden, R., Wilson, P., Harris, M., \& Spencer, V. (2001). Quadrupole ion storage tandem mass spectrometry and high-resolution mass spectrometry: complementary application in the measurement of $2,3,7,8$ chlorine substituted dibenzo-p-dioxins and dibenzofurans in US foods. Chemosphere, 43(4-7), 407-415.

Hoojjat, P., Harte, B. R., Hernandez, R. J., Giacin, J. R., \& Miltz, J. (1987). Mass transfer of BHT from high-density polyethylene film and its influence on product stability. Journal of Packaging Technology, 1(3), 78-81.

Jones, P. R. H., Ewen, R. J., \& Ratcliffe, N. M. (1998). Simple methods for the extraction and identification of amine malodurs from spoiled foodstuffs. Journal of Food Composition and Analysis, 11, 274-279.

Kiene, R. P. (1990). Dimethyl sulfide production from dimethylsulfoniopropionate in coastal seawater samples and bacterial cultures. Applied Environmental Microbiology, 56(11), 3292-3297

Laguerre, M., Mestres, C., Davrieux, F., Ringuet, J., \& Boulanger, R. (2007). Rapid discrimination of scented rice by solid-phase microextraction, mass spectrometry, and multivariate analysis used as a mass sensor. Journal of Agricultural and Food Chemistry, 55, 1077-1083.

Lopez, A., Williams, H. L., \& Ward, D. R. (1981). Essential elements in raw, boiled, steamed, and pasteurized crabmeat. Journal of Food Science, 46, 1128-1131.

Matiella, J., \& Hsieh, T. (1990). Analysis of crabmeat volatile compounds. Journal of Food Science, 55(4), 962-966.

McLafferty, F. W. (2000). The Wiley registry of mass spectral data (7th ed.). New York: John Wiley and Sons, Inc.

Meilgaard, M., Civille, G. V., \& Carr, B. T. (2007). Sensory evaluation techniques (pp. 189-253). Boca Raton, FL: CRC Press.

Mildner-Szkudlarz, S., Jeleń, H. H., Zawirska-Wojtasiak, R., \& Wąsowicz, E. (2003). Application of headspace - solid-phase microextraction and multivariate analysis for plant oils differentiation. Food Chemistry, 89, 515-522.

Miltz, J., Hoojjat, P., Han, J. K., Giacin, J. R., Harte, B. R., \& Gray, I. J. (1988). Loss of antioxidants from high-density polyethylene its effect on oatmeal cereal oxidation. In J. H. Hotchkiss (Ed.), ACS Symposium Series 365. Food Packaging Interactions (pp. 83-93). Washington, DC: American Chemical Society.

Pawliszyn, J. (1997). Solid phase microextraction: Theory and practice. New York: VCH.

Pivarnik, L., Ellis, P., Wang, X., \& Reilly, T. (2001). Standardization of the ammonia electrode method for evaluating seafood quality by correlation to sensory analysis. Journal of Food Science, 66(7), 945-952.

Powers, W. J., van Kempen, T., Bundy, D. S., Sutton, A., \& Hoff, S. J. (2000). Objective measurement of odors using gas chromatography/mass spectrometry and instrumental technologies. In Second international conference on air pollution from agricultural operations, October 9-11. Des Moines, IA: ASAE.

Robacker, D. C., \& Bartelt, R. J. (1996). Solid-phase microextraction analysis of staticair emissions of ammonia, methylamine, and putrescine from a lure for the Mexican Fruit Fly (Anastrepha ludens). Journal of Agricultural and Food Chemistry, 44, 3554-3559.

Schwope, A. D., Till, D. E., Ehntholt, D. J., Sidman, K. R., Whelan, R. H., Schwartz, P. S., et al. (1987). Migration of BHT and Irganox 1010 from low-density polyethylene (LDPE) to foods and food-simulating liquids. Food and Chemical Toxicology, 25(4), 317-326.

Smith, R., Nickelson, R., Martin, R., \& Finne, G. (1984). Bacteriology of indole production in shrimp homogenates held at different temperatures. Journal of Food Protection, 47, 861

Snellings, S. L., Takenaka, N. E., Kim-Hayes, Y., \& Miller, D. W. (2003). Rapid colorimetric method to detect indole in shrimp with gas chromatography mass spectrometry confirmation. Journal of Food Science, 68(4), 1548-1553.

Spink, A., Goodrum, A., Veciana-Nogues, M. T., Albala-Hurtado, M. S., IzquierdoPulido, M., \& Vidal-Carou, M. C. (1996). Validation of a gas-chromatographic method for volatile amine determination in fish samples. Food Chemistry, 57, 569-573.

Storelli, M. M., Giacominelli-Stuffler, R., Storelli, A., \& Marcotrigiano, G. O. (2003). Polychlorinated biphenyls in seafood: contamination levels and human dietary exposure. Food Chemistry, 82, 491-496.

Suyama, M., \& Konosu, A. (1987). Postmortem changes in fish and shellfish, in marine food science (Suison Shokuhin-Gaku) (p. 95). Tokyo: Koseisha, Koseikaku.

Ugland, H. G., Krogh, M., \& Rasmussen (1999). Automated determination of 'Ecstasy' and amphetamines in urine by SPME and capillary gas chromatography after propylchloroformate derivatisation. Journal of Pharmaceutical and Biomedical Analysis, 19, 463-475.

United States Department of Commerce. (2009). NOAA Handbook 25 - United States Standards for Grades of Fresh and Fozen Shrimp. Seafood Inspection Program (Vol. 2009). http://www.seafood.nmfs.noaa.gov/ NOAA\%20Handbook25/NOAA\%20Handbook.pdf (accessed 20.8.09).

Watts, D. A., \& Brown, W. D. (1982). Histamine formation in abusively stored Pacific mackerel: effect of $\mathrm{CO}_{2}$-modified atmosphere. Journal of Food Science, 47, 1386

Yerlikaya, P., \& Gökoðlu, N. (2004). Quality changes of blue crab (Callinectes Sapidus) meat during frozen storage. Journal of Food Quality, 27, 83-89. 